\title{
U-topias (urbanas) \\ do pensamento sociológico
}

FRAYA FREHSE

$\mathrm{B}$ OA PARTE das contribuições apresentadas no Seminário Internacional sobre Sociologia e Esperança remeteram à relevância do tempo - histórico, social, biográfico - para a compreensão dos vínculos da sociologia com a esperança. Partindo, com Henri Lefebvre (2000, p.114, 136), do reconhecimento de que o tempo é indissociável do espaço - "o tempo se inscreve no espaço" e "toda realidade no espaço se expõe e explica por uma gênese no tempo" -, viso problematizar a relação da sociologia com a esperança a partir justamente dos vínculos espaçotemporais que a disciplina nutre com esse sentimento humano particular que é a esperança, "estado de espírito" que acompanha a fé, a "certeza do incerto" (Fromm, 1979, p.27-8).

Considero que o espaço constitui “um conjunto de relações entre as coisas (objetos e produtos)" socialmente produzidas que interferem na produção da vida em sentido amplo (Lefebvre, 2000, p.100, xx). Mediação, o espaço não existe "em si", mas remete ao tempo, outra mediação, embora essa relação se proponha de modos socialmente diversos (Lefebvre, 2001, p.259). Por sua vez, pensamento sociológico alude ao rol de conceituações sobre a vida social publicizadas como "sociológicas" por seus autores ou terceiros que a elas recorrem em contextos acadêmicos diversos. O seu "ponto de referência" é específico: a "teia de interações e de relações sociais" em que se inserem as atividades ou comportamentos de cunho social que o sociólogo visa descrever sociologicamente (Fernandes, 1970, p.20-1).

Ora, ao mobilizarem conceituações sociológicas para interpretar os vínculos sociais entre os seres humanos e desses com o mundo material, também os sociólogos contribuem para a produção de espaço-tempo. De fato, pela linguagem eles produzem "lugares” histórica e socialmente específicos, "espaço-tempo locais" a que corresponde um uso do espaço, "prática espacial” produtora de espaço e que palavras como "lugar" dizem e compõem (Lefebvre, 2000, p.21, 23-4, 48). Sob esse prisma, o que será que os lugares produzidos conceitualmente pelo pensamento sociológico revelam sobre a relação da disciplina com a esperança?

Nesse sentido, interessam lugares específicos que os sociólogos, em contextos acadêmicos diversos do Ocidente desde os primórdios da disciplina, a partir de "meados do século XIX" (Ianni, 1989, p.8), privilegiaram para colocar em prática a sua própria esperança. Essa, afinal, não se dá no vazio. Expressa-se 
por referência a espaços prenhes de significados historicamente produzidos e localizados: lugares associados conceitualmente a possibilidades de uma ordem social outra, alternativa.

De fato, é por meio de representações que a variedade de lugares empiricamente existentes se tornam presentes na reflexão sociológica. A representação é "substituto da presença na ausência" (Lefebvre, 1980, p.240). No entanto, "toda” representação implica necessariamente um valor, "seja que o sujeito valoriza ou não aquilo que representa para si, o objeto ausente" (ibidem, p.47). Eis por que lugares definidos, no interior da multiplicidade daqueles vividos e/ ou investigados pelos sociólogos em seu dia a dia, viram lugares de esperança da sociologia. Eles são imbuídos de atributos valorativamente positivos, por referência ao futuro da ordem social respectivamente problematizada. E isso para além do eventual comprometimento do sociólogo com a célebre "neutralidade axiológica". É o que me leva a denominar tais lugares $u$-topias do pensamento sociológico. Com hífen, o termo sublinha a etimologia de "utopia" - "não lugar” em grego -, sem abdicar do estatuto de representação próprio das utopias (ibidem, p.94).

Dentre as u-topias da sociologia - que vão do "Estado" à "comunidade", passando por cidades, "esfera pública" e "espaços públicos" -, importam, nos limites deste ensaio, justamente urbes que, desde os primeiros tempos da disciplina na Alemanha, na França, nos Estados Unidos e no Brasil, têm sido conceitualmente referenciadas para explanar características da vida social ali. ${ }^{2}$ Em meio à sua absoluta variedade empírica, cidades definidas viraram objetos de representações de cidade - no singular, como "espaço moldado, modelado, ocupado pelas atividades sociais no decorrer de um tempo histórico" (Lefebvre, 2000, p.89). Tornaram-se u-topias urbanas, lugares imbuídos, aos olhos dos respectivos sociólogos, de possibilidades de transformação efetiva de padrões presentes de convivência social, por referência ao passado e com vistas a um futuro valorativamente esperado.

Buscar u-topias dos primeiros tempos da sociologia nesses quatro contextos nacionais, e seus desdobramentos conceituais mais recentes em momentos variados entre os anos 1950 e de 2000, evidencia o papel mediador que representações de tempo em relação ao espaço - no caso, urbano - exercem nos vínculos do pensamento sociológico com a esperança. Representações de cidade imbuídas de concepções de tempo pautadas por uma suposta interdependência entre passado e presente indicam reflexões mais "esperançosas" dos sociólogos acerca das cidades conceituadas. Já em concepções de cidade apoiadas na representação de um presente desvencilhado do passado transparece o contrário.

Para demonstrar o argumento, são decisivas imagens de cidade que, propostas por pioneiros da história das conceituações sociológicas sobre a cidade na Alemanha, na França, nos Estados Unidos e no Brasil, têm sido atualizadas nas últimas seis décadas. Tais imagens remetem a três u-topias urbanas. Em 
conjunto, essas evidenciarão, ao final, a importância metodológica de concepções de tempo em relação ao espaço (urbano), na problematização dos vínculos da sociologia com a esperança. E se elucidará por outro ângulo a atual pouca esperança da disciplina.

\section{Quando muitas imagens revelam três u-topias}

Apesar de serem "obras simbólicas individuais" que "trazem a marca do "inventor, poeta espontâneo ou cultivado", imagens articulam expressivamente emoções individuais e grupais passadas ao presente e ao futuro (Lefebvre, 1961, p.288). Assim, elas resultam não somente dos vínculos mais ou menos cotidianos dos respectivos sociólogos com as cidades que conceituam, e de sua formação teórica e metodológica. São "formas" que assumem as representações, integrando o imaginário, "relação da consciência (refletida, subjetiva) com o real" da qual justamente as representações são mediações (Lefebvre, 1980, p.240, 56).

Nos cenários acadêmicos em foco, as imagens de cidade estão impregnadas de alusões valorativas a tempos históricos - passado, presente e futuro. Assim, tornam-se metodologicamente reveladoras de representações definidas de espaço. É que carregam indícios de representações de tempo também específicas mobilizadas pelos respectivos sociólogos. São concepções prenhes de "esperanças, aspirações e propósitos" - parodiando Karl Mannheim (1968, p.233-4) sobre o papel metodológico do "sentido de tempo histórico" para a compreensão da "estrutura interna da mentalidade de um grupo". Mas esses anseios temporais não estão soltos no ar. Expressam-se espacialmente; no caso, em atributos associados a essas cidades: alienação, liberdade, autonomia, bem, mal, diferença.

\section{A cidade desalienadora}

Um primeiro lugar urbano de esperança sociológica se insinua em textos de Friedrich Engels e Karl Marx dos meados do Oitocentos na Inglaterra da díade industrialização-urbanização. É a cidade como lugar de possibilidades sui generis de desalienação dos seres humanos. A urbe favoreceria a tomada de consciência, pelos homens, de possibilidades de desenvolvimento social que, implícitas na constituição do gênero humano, haveria como realizar praticamente ali.

Em A situação da classe trabalhadora na Inglaterra, Engels (1972, p.256) esboça uma imagem de Londres em que o melhor e o pior da "civilização" se conjugam dialeticamente: "estes londrinos tiveram que sacrificar a melhor parte da sua humanidade" em prol da realização de "todos os milagres da civilização" de que a cidade é "prenhe". Se, pois, ali ocorre abertamente a "guerra social" de "todos contra todos" própria da "época industrial" (ibidem, p.257, 285), ali encontra abrigo também, mesmo que só em germe, o melhor da condição humana de seus habitantes.

É em $A$ ideologia alemã essa imagem receberá um tratamento conceitual bem mais elaborado. Referenciada à história da divisão do trabalho "no interior 
de uma nação" - que conduziria à "separação da cidade e do campo e à oposição de seus interesses" (Marx \& Engels, 1987, p.29) -, "a cidade" vira cenário privilegiado da "alienação". Afinal, o primeiro "exemplo" dessa é a divisão do trabalho, "mais desenvolvida" na cidade separada do campo (ibidem, p.28, 31). Ora, alienação designa o estranhamento dos homens em relação ao caráter humano genérico de suas próprias ações, à natureza social da práxis: "a própria ação do homem converte-se num poder estranho e a ele oposto, que o subjuga ao invés de ser por ele dominado" (ibidem, p.47). Embora intrínsecas ao ser humano como gênero (Marx, 1961), as condições que tornam o indivíduo estranho a si mesmo se potencializam notadamente nas urbes da industrialização capitalista, na proporção do incremento do "poder social" nesse contexto, "força produtiva multiplicada que nasce da cooperação de vários indivíduos exigida pela divisão do trabalho" (Marx \& Engels, 1987, p.49). Ao mesmo tempo, contudo, é em tais cidades que há como "superar" a alienação - e instaurar o comunismo. Embora os autores não sejam explícitos nesse sentido, é ali que insinuam a presença da "massa da humanidade [...] totalmente "destituída de propriedade" e "em contradição com um mundo de riquezas e de cultura existente de fato" (ibidem, p.50)?

Marcadas por tais características, as urbes imaginadas por esses dois alemães colaboram de modo pioneiro para alçar ao menos as grandes urbes do capitalismo internacional Oitocentista a u-topias dos primórdios do pensamento sociológico na Europa. Expondo as agruras sociais desse modo de produção, as cidades potencializariam a conscientização e superação desses dramas, como capítulos do processo histórico de constituição do gênero humano.

Essa representação tem tido vida longa na sociologia dedicada ao espaço urbano. Crucial é, em particular, a reflexão dialética de Lefebvre sobre a cidade, o urbano e o espaço das décadas de 1960 e 1970. Forjada em reavaliações críticas de Marx, Hegel e Nietzsche à luz da importância social e cultural da vida cotidiana no capitalismo do segundo pós-guerra, a cidade constitui mediação reveladora das contradições históricas que aproximam e afastam os seres humanos de uma possibilidade histórica sui generis que a própria cidade, como obra historicamente produzida, favorece e dificulta: o "urbano". É a "simultaneidade", o "encontro" das diferenças, "da obra e do produto", por cuja mediação o homem se humaniza, e que, na virada de 1970, são uma "realidade social virtual" mais e mais problemática, em meio à tendência generalizada de "explosão-implosão" dos antigos núcleos urbanos - embora autor destaque Paris (Lefebvre, 1969, p.50, 77, 86; 1970a, p.13).

Embora dialogue com a u-topia marxiana da cidade como lugar de possibilidades históricas de desalienação, a conceituação lefebvriana também a transforma. Investe na potencialização das diferenças. Em $O$ manifesto diferencialista (Lefebvre, 1970b), a filiação explícita à proposta marxiana (Marx, 1961) da "emancipação humana" vem junto com a ênfase no "direito à diferença" - ao 
encontro (mais ou menos tenso) de particularidades (qualidades) irredutíveis; à relação forjada em relações vividas como recíprocas, conflituosas ou apaziguadas (Lefebvre, 1970b, p.44, 64-5). A realidade espacial privilegiada para isso? O urbano, cujo "corolário" é "a formação, 'em campo', de um espaço-tempo diferencial" (ibidem, p.129). Advém dessa aposta metodológica - e valorativa - o enfoque analítico na tríade "iso-topia", "hetero-topia" e "u-topia", passível de revelar o "espaço diferencial no espaço urbano". Notadamente a u-topia, "lugar daquilo que não tem nem lugar", seria crucial para o pensamento (ibidem, p.53, 179).

O fato de nas últimas décadas a influência teórica e metodológica das ponderações lefebvrianas sobre o espaço ter se renovado nos quatro cantos do mundo (Stanek, 2011, p.xiv-xv) evidencia certa atualidade da velha u-topia sociológica da cidade como lugar de emancipação humana possível. Dos quatro contextos acadêmicos em foco, aludo, por exemplar, a imagens de inspiração metodológica lefebvriana que José de Souza Martins (1992, 2008a, 2008b) esboça acerca de São Paulo. O centro dessa teria adentrado o século XX marcado pela "alienação de um saber sem raiz, $[. .$.$] de um divórcio profundo entre o con-$ cebido e o vivido", e, mais recentemente, teria perdido "sua monumentalidade e suas virtudes urbanas e urbanizadoras, emancipadoras e libertadoras, seu adensamento cultural". Tudo isso embora "megacidades" como São Paulo sejam "cenários de desafios e de possibilidades", expressando "mudanças adaptativas no modo de vida dos milhões de pessoas que nelas vivem", e "a emergência de notáveis possibilidades de transformação social no sentido do primado do homem, de sua liberdade, de sua imaginação e de sua criatividade" (Martins, 1992, p.11; 2008a, p.53; 2008b, p.J5).

Vale ressaltar que provém da mesma virada dos anos 1970 na França um segundo desdobramento sociológico bem influente da u-topia urbana marxiana. Articulando o estruturalismo althusseriano com a reflexão de Touraine sobre a ação política dos movimentos sociais, para Manuel Castells (1979, 1983, 2000, 2002 ) as cidades são estruturas espaciais de relações sociais próprias do mundo capitalista de então. Conformando, nesse contexto, "sistemas" organizados em torno do consumo coletivo de bens, as cidades seriam "pontos de contradição e de conflito entre a acumulação do capital e a redistribuição social, entre o controle estatal e a autonomia do povo" (Castells, 2000; 2002, p.11). Em torno desses temas emergem "novas formas da luta de classes" (Castells, 1979, p.15; 2000) protagonizadas pelos chamados movimentos sociais urbanos, cujas possibilidades históricas de atuação Castells (1983) acompanhou sobretudo até os anos 1980.

Referencial em especial nos estudos urbanos latino-americanos da época (Gorelik, 2005), a aposta castellsiana nas virtudes políticas dos movimentos sociais urbanos encontrou um desenvolvimento conceitual original, entre outros, em Lúcio Kowarick $(1979,2000)$. Esse reconheceu "consequências" do tipo 
de desenvolvimento capitalista no Brasil do século XX não somente no tipo de exploração do trabalho vigente em São Paulo, mas na "própria condição urbana de existência a que foi submetida a classe trabalhadora" (Kowarick, 1979, p.41), cuja lógica espoliativa o autor inquire investigativamente desde então. Embora mais recentemente tenha salientado que "as utopias libertárias se perderam", sublinhou também restar "o ideário de uma concepção que se constrói a partir da luta da sociedade civil e que passa necessariamente, e cada vez mais, pela questão da democracia", em prol da crença no "enorme potencial ocioso de historicidade" abrigado na América Latina (Kowarick, 2000, p.134).

Dotada de ênfases que vão da humanidade à autonomia do povo e à democracia, a u-topia urbana da desalienação humana bem poderia ser associada a uma segunda que reconheço forte nos primeiros tempos do pensamento sociológico - só que na Alemanha, França e nos Estados Unidos.

\section{A cidade modernizadora}

Urbes são representadas como lugares de possibilidades peculiares de realização desse ideário, de modernização da vida social. Ganham destaque anseios sobre o ser humano historicamente forjados na Europa e nos Estados Unidos das revoluções dos séculos XVIII e XIX, e difundidos pelo mundo na esteira de difusão social da modernidade como realidade social e cultural pautada pela concepção de que tudo e todos são transitórios, moda, modernos. Refiro-me às ideias de liberdade, igualdade e racionalidade, com suas contrapartidas de diferenciação social e cultural.

Decerto essas concepções permeiam também o solo histórico no qual emergiu a u-topia urbana das possibilidades de desalienação humana. Associo tais ideias a uma segunda representação para evidenciar que a ênfase aqui reside em valores da modernidade tributários do pressuposto de que os seres humanos empiricamente existentes e o ser humano genérico se equivaleriam. Estamos longe de Marx e Lefebvre, para os quais o gênero humano é uma virtualidade teórica e prática (e política) cujo processo de constituição é essencialmente contraditório. ${ }^{3}$

Uma evidência sintética do ingresso da cidade modernizadora no imaginário sociológico é a imagem urbana que permeia um ensaio célebre de Georg Simmel (2005). Como "lugar da economia monetária", a cidade grande - e a referência empírica sub-reptícia é Berlim - seria palco preferencial "para o conflito e para as tentativas de unificação" dos dois tipos de individualismo próprios da "vida do espírito" de seu "habitante": a liberdade, "clamada" pelo "homem" do século XVIII, ao lado da "particularidade humana e de suas realizações, dadas pela divisão do trabalho" oitocentista. A tese é dupla. Autonomia e diferenciação individuais integrariam a "vida moderna" em particular na cidade grande, a qual paradoxalmente desafia tais atributos por fomentar a "intensificação da vida nervosa", à diferença de "campo" e "cidade pequena" (Simmel, 2005, p.577-8, $589)$. 
Liberdade e diferenciação individuais assumem, assim, o estatuto valorativo de possibilidades próprias das cidades grandes. E isso a despeito de todas as forças em contrário que nessas urbes também existiriam de modo único; condição, aliás, que impediria "julgá-las”: só caberia "compreendê-las" (Simmel, 2005, p.589).

Embora no Max Weber (2004) do ensaio inacabado sobre "A cidade" o método de interpretação não se paute por paradoxos, repõe-se a ênfase conceitual em características modernas das cidades. De fato, é vasta a tipologia de urbes ali. Como, porém, o autor busca conexões de sentido entre a história das cidades antigas e medievais na Europa, Ásia e Oriente Médio, e o processo histórico de racionalização próprio do capitalismo em particular na Alemanha do início do século XX, ganham destaque atributos da vida social nas cidades medievais do centro-norte europeu que compartilhariam muito com a "cidade moderna (Londres, Paris, Berlim, [...] Düsseldorf)" (Weber, 2004, p.412). As "especificidades da cidade ocidental" girariam em torno da liberdade (na posse de bens de raiz, na situação jurídica pessoal) e da "associação" (institucional, autônoma) dos "cidadãos", por interesses racionais; tanto que "totalmente estranhos" foram às vezes incorporados (ibidem, p.425-45).

Nesse sentido, a imagem contribui a seu modo para a u-topia urbana em tela. Se a obra de Weber é critica do processo de racionalização ocidental, o estudo das cidades sugere que a liberdade e a racionalidade da cidade moderna são possibilidades históricas em germe no passado medieval europeu. Para contornar seus dilemas contemporâneos, lamentados ao final de A ética protestante e o espírito do capitalismo, nada como a política - da qual Weber foi ferrenho defensor.

De que o vigor dessa u-topia urbana não é apanágio dos sociólogos alemães da época é exemplar o foco durkheimiano (Durkheim, 2004) nos méritos valorativos explícitos da corporação medieval - empiricamente própria de cidades europeias - para a contenção do individualismo da sociedade moderna. Com efeito, esse tipo de valorização positiva das urbes medievais é indissociável de um movimento intelectual mais amplo nos primórdios da sociologia na Europa: "De repente, a Idade Média volta a ser objeto da atenção humanista" (Nisbet, 1981, p.55, 57).

Mas há mais. Basta buscar a reflexão sociológica sobre a cidade na Universidade de Chicago a partir da década de 1910. Em sua versão definitiva, o pioneiro programa de "investigação do comportamento humano no ambiente urbano", de Robert E. Park (1967), associa ecologicamente a cidade ao "hábitat natural do homem civilizado", mas também a uma "área cultural caracterizada por seu tipo cultural peculiar", nos termos de um best-seller alemão da época: "todas as grandes culturas nasceram na cidade. $\mathrm{O}$ homem proeminente na segunda geração é um animal construtor de cidades" (Spengler apud Park, 1967, p.2-3). Embora os temas investigativos elencados no texto remetam a problemas 
sociais próprios da urbe conflituosa e desigual que era Chicago então, importa que, ao mesmo tempo, a "cidade grande" é berço da "civilização" humana. Essa categoria, própria do ideário político moderno na França, sugere a relevância que, na cidade imaginada por Park, têm atributos próprios do mundo moderno. Não surpreende, pois, que no final do texto seja destacada a diversidade moral da cidade, "em função da oportunidade que [essa] oferece, especialmente aos excepcionais e anormais": ela "mostra em excesso o bem e o mal da natureza humana" (Park, 1967, p.46).

A formulação assegura à cidade civilizada do autor um caráter valorativamente paradoxal próprio da cidade moderna simmeliana. Com efeito, Park frequentou aulas de Simmel em Berlim e traduziu textos seus (Lindner, 2004, p.120-1). Mas também a cidade medieval moderna de Weber importa implicitamente, em outro momento do texto (Park, 1967, p.12).

Isso, quando essa urbe não orienta de modo explícito, ao lado da simmeliana, a reflexão do respectivo sociólogo de Chicago. É o que ocorreu no Louis Wirth (1938) da aposta no "urbanismo como modo de vida".

Contemplada retrospectivamente, a u-topia que essas imagens evidenciam pode parecer datada. Não apenas a Segunda Guerra Mundial e as lutas de descolonização posteriores destruíram a crença nas virtudes emancipatórias de razão, liberdade e igualdade ocidentais. Também o movimento pós-moderno colaborou para evidenciar o caráter histórico, político e social relativo de tudo isso (Harvey, 1992). No entanto, nem por isso a sociologia dos últimos sessenta anos nos quatro cenários em foco deixa de registrar abordagens que atualizam diversamente essa u-topia.

A aposta conceitual da sociologia latino-americana da década de 1950 e de parte de 1960 na díade urbanização-industrialização se nutriu de modo contundente da chamada teoria da modernização de inspiração weberiana (Gorelik, 2005 , p.117-18). É à luz desse contexto que se compreende, por exemplo, uma imagem tão explicitamente valorativa sobre a urbanização paulistana como a de Florestan Fernandes (1960, p.191):

Tendo-se em vista as condições em que se processaram [em São Paulo] a desagregação da antiga ordem social escravocrata e senhorial e a formação incipiente da nova ordem de classes sociais, a urbanização representa e assegura a evolução para situações sociais de vida historicamente desejáveis no Brasil. (grifos meus)

Outro indício: a proposição institucional de uma "sociologia rural", nos anos 1960, parte da expansão não ambígua do urbano sobre o rural - e do racional sobre o tradicional etc. (Martins, 1981, p.23).

Mas a u-topia em questão também conta com desdobramentos bem menos datados, aos olhos de hoje. Penso, por um lado, em certa sociologia norte-americana recente que, em diálogo com as ponderações sociológicas de Erving Goffman - da chamada segunda geração da Escola de Chicago - sobre a 
lógica social das situações de interação social, tem ressaltado os vínculos valorativamente positivos entre a cidade e o estranho (Lofland, 1985, 1998; Sennett, 1978, 2005). São propostas que tangenciam apostas valorativas na igualdade e na liberdade implícitas, em primeira instância, na abordagem simmeliana da sociabilidade entre anônimos na cidade moderna (cf. em particular Lofland, 1998). Quanto a Weber, há quem o reconheça na linha teórica que permite a Richard Sennett associar à cidade a suposta liberdade implícita nas possibilidades de inserção social do estranho ali (Martins, 2008b).

Refiro-me, por outro lado, a uma sociologia francesa que, nas últimas décadas, enfatizou as virtudes comunicativas dos espaços públicos onde os estranhos interagem, e que particularizariam a cidade como tal (Joseph, 1991, 1998). A figura do "citadino", essencialmente aberto à comunicação, resulta da atualização crítica da ênfase de Chicago nas interações na cidade, por meio de um retorno a Simmel.

Isso tudo para não falar na verdadeira tradição de estudos sociológicos alemães do segundo pós-guerra em torno da problemática da "urbanidade" (cf. a respeito Frehse, 2010, p.10-11). Recorrendo a atributos conceituais da cidade moderna de Simmel e Weber, e ao urbanismo de Wirth, autores diversos têm avaliado mais ou menos criticamente, com o auxílio da noção, a realidade urbana empiricamente vigente na Alemanha. De fato, urbanidade é assumida por um de seus mais vigorosos defensores recentes (Siebel, 1994) como "resultado de processos sociais" que teriam feito, ao longo dos séculos, da "cidade europeia" um lugar onde a história é presente na vida cotidiana de seus habitantes; lugar de encontros mais ou menos conflituosos com o estranho e abrigo para comportamentos desviantes; lugar de conflito "consciente" de interesses; e de liberdade, emancipação e contradição.

Explicitados todos esses aspectos, chegamos a uma terceira e última utopia. Considerando-se os contextos em foco, ela se insinua em particular no Brasil.

\section{A cidade diferente em relação ao moderno}

Enquanto os primórdios de Chicago evidenciam uma sociologia que se nutriu valorativamente sem mediações de u-topias alemãs da modernização da vida social nas cidades, os primeiros tempos da disciplina no Brasil, nos anos 1930, sugerem a importância contrapontística dessa u-topia. A cidade abriga possibilidades históricas sui generis de diferenciação em relação à modernidade europeia - e norte-americana.

É provável que boa parte disso se deva à ênfase explicativa que o "passado" assume no pensamento social que se estabelece no país então, tornando-se uma marca da primeira geração de sociólogos ali formados (Candido, 2006a, p.232s). Indissociável da "curiosidade acentuada" dos intelectuais brasileiros da época em "conhecer o país e, em sentido mais amplo, a sociedade moderna e seus problemas" (Candido, 2006b, p.284), o enfoque sociológico sobre o pas- 
sado do mundo urbano no Brasil aparece de modo pioneiro não apenas no Gilberto Freyre (2000) de Sobrados e mucambos, mas em trechos de Raizes do Brasil em que o historiador Sérgio Buarque de Holanda (2006, p.67-184) recorre contrapontisticamente às ponderações weberianas sobre as cidades e o processo de racionalização ocidental no serviço público, a fim de explanar características da urbanização no Brasil do século XIX.

Em abordagens respectivamente culturalista e sócio-histórica, as grandes cidades oitocentistas do país são imaginadas como lugares cujos traços culturais e processos sócio-históricos diferem daqueles presentes nas cidades europeias que povoam conceitualmente o imaginário dos dois autores nessas obras. Freyre (2000, p.11) enfatiza que, "com o desenvolvimento das cidades e das indústrias" e o "declínio do patriarcado rural no Brasil", as distâncias sociais teriam, de um lado, diminuído ao longo do século XIX, mas, de outro, aumentado e se tornado mais frequentes os "atritos entre os homens, que a Revolução Industrial excitou em nosso meio". E, no entanto, teriam se definido também, nas cidades do período, "contemporizações" bem "brasileiras" entre os extremos sociais: procissões, festas de igreja, o entrudo e o carnaval constituiriam "momentos de confraternização" que fizeram das ruas e praças "zonas de confraternização" (ibidem, p.13, 16).

Buarque de Holanda (2006, p.88-9), por sua vez, sublinha que "o processo de crescimento dos núcleos urbanos" veio de mãos dadas com o "desenvolvimento da tradicional situação de dependência" das "cidades em face dos domínios agrários", alterando a distinção "clássica e tipicamente europeia" entre cidade e aldeia em prol de "meio urbano e a 'fazenda", a qual teria marcado "toda a ordem administrativa do país" no Império e República. É, entre outros, essa especificidade que a Abolição teria colocado em xeque, "marco" de uma "revolução lenta" cujo destino - democracia ou autoritarismo - ainda restava em aberto, em 1936 (ibidem, p.126).

Pontilhadas por tal atenção analítica às diferenças historicamente forjadas entre as cidades brasileiras e as europeias, ambas as imagens sugerem apostas valorativas de seus autores nas possibilidades históricas de um futuro específico "brasileiro" - contidas nessas diferenças. Para o bem ou para o mal.

Mas eles não estavam sós. A sociologia se institucionalizou na pioneira Universidade de São Paulo pela mão de gente como Roger Bastide (1987, p.188), cuja prática docente visou "tirar da realidade uma teoria brasileira, e não impor aos fatos brasileiros uma sociologia nascida na América do Norte ou na Europa”.

Dito tudo isso, considere-se que provavelmente esse tipo de ênfase na busca da diferença em relação ao moderno europeu e/ou norte-americano - e a u-topia urbana que ela encerra - não é apanágio dos primórdios da sociologia no Brasil. Se escaparia aos intuitos deste ensaio aprofundar tal aspecto, lembro que é de cenários acadêmicos periféricos à Europa e aos Estados Unidos que têm 
emergido, a partir dos anos 1990, clamores conceituais em prol de noções não eurocêntricas de modernidade - e de uma sociologia "descolonizada" (Boatca et al., 2010).

Quanto à u-topia urbana ora em jogo, ela reaparece em momentos posteriores da trajetória da reflexão sociológica sobre as cidades no Brasil. O mesmo Fernandes que abraçou valorativamente, por meio do método funcionalista, as virtudes modernizadoras da urbanização, salientou a presença vigorosa de "alguns componentes rurais" no presente metropolitano paulistano dos anos de 1950 - abrindo espaço interpretativo para diferenças da realidade urbana nacional em relação ao contexto norte-americano, referência empírica primeira para a reflexão sobre o “'continuum' rural-urbano”, com o qual Fernandes (1960, p.192, 191) trabalha. Já na década de 1970, Maria Isaura Pereira de Queiroz (1978, p.47) salientou, com base em uma análise do passado paulistano oitocentista, que, à diferença de Europa e Estados Unidos de então, no Brasil urbanização não coincide com industrialização.

É à luz dessa linhagem de preocupações teóricas que se compreende também por que Kowarick e Martins, formados nessa tradição acadêmica, se preocuparam até recentemente com as especificidades da urbanização no Brasil: seu caráter excludente e predatório (Kowarick, 2009), residual (Martins, 2008b). Assim nos reaproximamos, por outro ângulo, da primeira u-topia aqui elencada: em busca de possibilidades teóricas - e históricas - de diferença no Brasil urbano atual, a dialética de inspiração marxiana continua sendo reveladora...

\section{Entre a sociologia e a esperança (nas cidades), historicidade}

Sintetizadas as três u-topias e alguns de seus desdobramentos mais recentes em quatro contextos acadêmicos ocidentais, nota-se que, apesar de prenhes de problemas sociais, as cidades têm sido objetos também de anseios e expectativas de sociólogos que contribuíram significativamente, em termos conceituais, para a história dessas respectivas sociologias. Se só raramente a esperança nessas cidades é explícita, há como intuí-la. Basta levar em conta as concepções de tempo que impregnam as imagens e, assim, as três u-topias, por referência ao espaço urbano.

Nesse sentido, importa pouco o caráter teleológico que, muito próprio do pensamento social do século XIX, aparece no início da sociologia na Europa e nos Estados Unidos. De fato, para Marx o fim último da história é o comunismo, e seu "sentido", a "plenitude da própria racionalidade, a realização humana" (Lefebvre, 1971, p.21). Já em Simmel, Weber, Durkheim, o presente futuro é a cidade moderna, inseparável, por sua vez, em Park, de uma concepção linear de história, do mundo primitivo à civilização. Tais teleologias entraram em crise depois da Segunda Guerra, assim como a crença na modernidade como "projeto" (Habermas, 1985, p.9).

Mais interessa que sob o manto de finalismos históricos distintos - mais recentemente em xeque - se esconde a concepção de que o futuro das urbes 
em questão é indissociável do modo como passado e presente ali se combinam. As imagens resultam de encadeamentos interpretativos sobre os vínculos indissociáveis entre passado, presente e futuro, na realidade urbana respectivamente conceituada. É o que chamo de concepção histórica de tempo. A historicidade importa - e abre espaço para abordagens conceituais distintas (teleológicas ou não) das esperanças dos sociólogos nessas mesmas cidades.

Leitores pós-modernos deste ensaio poderiam alegar: são concepções de tempo próprias da modernidade, já ultrapassada! De fato, se a fragmentação, indeterminação e intensa desconfiança de todos os “discursos universais" são "o marco do pensamento pós-moderno" (Harvey, 1992, p.19), e isso implica a redução da experiência a "uma série de presentes puros e não relacionados no tempo" (Jameson, 1984, p.20, apud Harvey, 1992, p.57)...

Mas também essa é uma concepção específica, presentista de tempo em relação ao espaço. Insere-se, aliás, em uma tendência mais ampla prognosticada por Lefebvre (2000, p.114): "o tempo desaparece no espaço social da modernidade". Desse ângulo, articular passado, presente e futuro no espaço não faz mesmo sentido.

O fato é que, sob o impacto mais ou menos explícito da chamada pós-modernidade, para não falar na globalização econômica e na tão propalada "crise das ideologias", essa concepção presentista de tempo adentrou também a reflexão sociológica recente sobre as cidades. É o que se percebe em imagens que, com orientações metodológicas distintas, se fundamentam temporalmente na suposição, por exemplo, de transformações "radicais" na estrutura social das cidades nas últimas décadas (Sassen, 1991, p.12); de um padrão absolutamente novo de consumo - "visual" - do tempo e do espaço (Zukin, 2000, p.81); de "muitas" alterações nos "tempos, espaços e ritmos da experiência urbana" a partir dos anos 1990 (Telles \& Cabanes, 2006, p.11). Se as complexidades sociais e culturais da conjuntura urbana contemporânea inegavelmente trazem novos desafios para a sociologia, formulações como essas evidenciam, por sua vez, que o presente nas cidades pode ser imaginado também como essencialmente distinto de tudo o que havia antes ali. Tanto que teriam se tornado obsoletos instrumentos conceituais até então comuns para pensar as urbes - e forjados em diálogo com o ideário da modernidade.

Com o olhar atento a concepções de tempo implícitas nas respectivas imagens de cidade, fica claro o caráter relativo até mesmo de associações conceituais como essas. Sobretudo quando a ruptura contundente do presente ante o passado assume ares de pressuposto analítico, embora constitua em si uma questão investigativa: mudança acentuada em relação a quê, se o próprio passado não existe "em si", como ensina a crítica foucaultiana da história - que fomentou a própria pós-modernidade?

Aqui, esse aspecto interessa menos do que o vínculo da sociologia com a esperança que a concepção presentista de tempo sinaliza. Nada de u-topia urbana. 
O que mal não faz ao pensamento sociológico, quando a esperança não está em pauta. Porém, quando, como no seminário que fomentou este ensaio, ela importa, as concepções de tempo em relação ao espaço urbano assumem uma relevância insuspeitada. Viram justamente referências metodológicas de vínculos distintos da sociologia com a esperança. A incursão imaginária aqui realizada sugere que representações históricas de tempo em relação ao espaço urbano são condições sine qua non para se discernir esperança na sociologia devotada às cidades. Quanto a outros lugares da esperança da disciplina, também eles precisariam ser submetidos ao parâmetro metodológico temporal - mas isso é tarefa para um outro momento.

A constatação lança nova luz sobre a chamada crise atual das esperanças na sociologia. Ora, é essencialmente ocidental a assunção da diferença entre passado, presente e futuro, para o conhecimento de fatos históricos (Koselleck, 1981). Não surpreende que a esperança entre em xeque quando, como atualmente na Europa, a sociologia leva a sério outras noções de tempo - a fim de se “descolonizar”.

Mas será então que não há mais espaço - e tempo - para a esperança na disciplina? Ao menos no caso das cidades, são sugestivos os desdobramentos mais recentes das três u-topias que conhecemos. Eles sinalizam que, em busca de esperança, uma via privilegiada para a sociologia é voltar a se sensibilizar com o tempo, na verdade com a historicidade dos processos sociais nas e fora das cidades.

O tempo de que precisamos, porém, é específico - e abre espaço para a minha própria esperança. Nada de evidenciar uma preferência valorativa prévia pelo moderno. É o que ocorreu no passado de fé cega nas virtudes da modernização. Tenho aprendido em minhas pesquisas que assumir metodologicamente o tempo histórico como mediação assegura à própria modernidade um papel metodológico crucial para o conhecimento crítico de possibilidades históricas contidas nos espaços urbanos no presente. E para o reconhecimento crítico da esperança mais ou menos ilusória contida nos espaços que a sociologia, ao estudar, produz.

Notas

1 São minhas as traduções de textos estrangeiros cuja indicação de tradução (Trad.) não aparecer nas Referências do artigo.

2 Selecionei esses contextos com relativa aleatoriedade, no âmbito de estudos mais amplos meus sobre a sociologia ocidental dedicada às cidades, inclusive como bolsista (2010) da Alexander von Humboldt Foundation, a quem sou grata.

3 Aliás, Marx e Engels criticam nos neo-hegelianos de fato a assunção do "Homem" (seus direitos, propriedade etc.) como realidade consumada, na Alemanha da época. 
Referências

BASTIDE, R. Entrevista com Roger Bastide [por I. Cardoso]. Discurso, São Paulo, n.16, p.181-97, 1987.

BOATCA, M. et al. (Ed.) Decolonizing European Sociology. London: Routledge, 2010.

CANDIDO, A. A sociologia no Brasil. Tempo Social, São Paulo, v.18, n.1, p.271-301, 2006a.

O significado de Raizes do Brasil. In: HOLANDA, S. B. de. Raizes do Brasil. Ed. rev. São Paulo: Cia. das Letras, 2006b. p.235-250.

CASTELLS, M. Problemas de investigação em sociologia urbana. Trad. Lisboa: Editorial Presença; São Paulo: Martins Fontes, 1979.

. The city and the grassroots. Berkeley: University of California Press, 1983.

. A questão urbana. Trad. Rio de Janeiro: Paz e Terra, 2000.

. Urban Sociology in the Twenty-First Century. Comunidades e Territórios, Lisboa, n.5, p.9-19, 2002.

DURKHEIM, E. A divisão do trabalho social. Trad. São Paulo: Martins Fontes, 2004.

ENGELS, F. Die Lage der arbeitenden Klasse in England. In: MARX, K.; ENGELS, F. Marx-Engels-Werke. Berlin: Dietz, 1972. v.2, p.225-506.

FERNANDES, F. Caracteres rurais e urbanos na formação e desenvolvimento da cidade de São Paulo. In: Mudanças sociais no Brasil. São Paulo: Difel, 1960. p.179-233.

Elementos de sociologia teórica. São Paulo: Edusp; Rio de Janeiro: Companhia Editora Nacional, 1970.

FREHSE, F. Blickwechsel: Zur deutschen Stadtsoziologie aus brasilianischer Perspektive. In: KOLLOQUIUM “BLICKWECHSEL”, 2010.

FREYRE, G. Sobrados e mucambos. 12.ed. Rio de Janeiro: Record, 2000.

FROMM, E. A revolução da esperança. São Paulo: Círculo do Livro, 1979.

GORELIK, A. A produção da “cidade latino-americana”. Trad. Tempo Social, São Paulo, v.17, n.1, p.111-33, 2005.

HABERMAS, J. Der philosophische Diskurs der Moderne. Frankfurt: Suhrkamp, 1985.

HARVEY, D. Condição pós-moderna. 5.ed. Trad. São Paulo: Edições Loyola, 1992.

HOLANDA, S. B. de. Raizes do Brasil. Ed. rev. São Paulo: Cia. das Letras, 2006.

IANNI, O. A sociologia e o mundo moderno. Tempo Social, São Paulo, v.1, n.1, p.7$27,1989$.

JOSEPH, I. (Dir.) L'espace du public. Paris: Recherches, 1991.

La ville sans qualités. La Tour d'Aigues: l'Aube, 1998.

KOSELLECK, R. Modernity and the Planes of Historicity. Trad. Economy \& Society, London/Boston/Henley, v.10, n.2, p.166-83, 1981.

KOWARICK, L. A espoliação urbana. Rio de Janeiro: Paz e Terra, 1979.

. Escritos urbanos. São Paulo: Editora 34, 2000.

. Viver em risco. São Paulo: Editora 34, 2009. 
LEFEBVRE, H. Critique de la vie quotidienne. Paris: L'Arche Éditeur, 1961. v.2. . O direito à cidade. São Paulo: Documentos, 1969. . La révolution urbaine. Paris: Gallimard, 1970a. . Le manifeste différentialiste. Paris: Gallimard, 1970b. . O fim da história. Lisboa: Dom Quixote, 1971. . La présence et l'absence. Paris: Casterman, 1980. . La production de l'espace. 4.ed. Paris: Anthropos, 2000. . Du rural à l'urbain. 3.ed. Paris: Anthropos, 2001.

LINDNER, R. Walks on the wild side. Frankfurt: Campus, 2004.

LOFLAND, L. A world of strangers. 2.ed. Prospect Heights: Waveland Press, 1985. . The public realm. New York: Aldine de Gruyter, 1998.

MANNHEIM, K. Ideologia e utopia. Trad. Rio de Janeiro: Zahar, 1968.

MARTINS, J. de S. As coisas no lugar. In: rural. São Paulo: Hucitec, 1981. p.11-38. . (Org.) Introdução crítica à sociologia

MARTINS, J. de S. Subúrbio. São Paulo: Hucitec; São Caetano do Sul: Prefeitura de São Caetano do Sul, 1992. A aparição do demônio na fábrica. São Paulo: Editora 34, 2008 a.

. A era das megalópoles residuais. O Estado de S. Paulo, São Paulo, 7.12.2008. Aliás, p.J4-J5, 2008b.

MARX, K. Zur Judenfrage. In: MARX, K.; ENGELS, F. Marx-Engels-Werke Berlin: Dietz, 1961. v.1, p.347-77.

MARX, K.; ENGELS, F. A ideologia alemã (I - Fenerbach). 6.ed. São Paulo: Hucitec, 1987.

NISBET, R. A. As ideias-elementos da sociologia. Trad. In: MARTINS, J. de S. (Org.) Introdução critica à sociologia rural. São Paulo: Hucitec, 1981. p.15-36.

PARK, R. E. The City: Suggestions for the Investigation of Human Behavior in the City Environment. In: PARK, R. E. et al. The city. Chicago: The University of Chicago Press, 1967. p.1-46.

QUEIROZ, M. I. P. de. Cultura, sociedade rural, sociedade urbana no Brasil. São Paulo, LTC; Edusp, 1978.

SASSEN, S. The Global City. New York, London, Tokyo. Princeton/Oxford: Princeton University Press, 1991. . The global city. Princeton: Princeton University Press, 2001.

SENNETT, R. El Declive del Hombre Público. Trad. Barcelona: Península, 1978. . The culture of the new capitalism. New Haven: Yale University Press, 2005.

SIEBEL, W. Was macht die Stadt urban? Oldenburger Universitätsreden, Olderburg, n.61, 1994.

SIMMEL, G. As grandes cidades e a vida do espírito. Trad. Mana, Rio de Janeiro, v.11, n.2, p.577-91, 2005. 
STANEK, L. Henri Lefebvre and Space. Minneapolis: The University of Minnesota Press, 2011.

TELLES, V. da S.; CABANES, R. Introdução. In: São Paulo: Associação Editorial Humanitas, 2006. p.11-28.

WEBER, M. A dominação não-legítima. In: Economia e sociedade. Brasília: Editora UnB; São Paulo: Imesp, 2004. v.2, p.408-517.

WIRTH, L. Urbanism as a way of life. The American Journal of Sociology, Chicago, v.44, n.1, p.1-24, jul. 1938.

ZUKIN, S. Landscapes of power. Berkeley: University of California Press, 1991. . Paisagens urbanas pós-modernas: mapeando cultura e poder. Trad. Silvana Rubino. In: ARANTES, A. A. (Org.) O espaço da diferença. Campinas: Papirus, 2000. p.80-103.

RESUMO - O que os lugares produzidos conceitualmente no pensamento sociológico revelam sobre a relação da sociologia com a esperança? A esperança dos sociólogos se expressa, entre outros, em representações de lugares associados a possibilidades históricas de ordens sociais outras. Enfocar notadamente u-topias urbanas dos primeiros tempos da sociologia na Alemanha, na França, nos Estados Unidos e no Brasil, e seus desdobramentos mais recentes, evidencia o papel metodológico de representações de tempo em relação ao espaço (urbano), nos vínculos da sociologia com a esperança. Em particular, concepções históricas de tempo em relação às cidades parecem decisivas para uma sociologia "esperançosa".

PALAVRAS-CHAVE: Sociologia, Tempo, Espaço, U-topia, Cidade.

ABSTRACT - What do the places conceptualized in sociological thought reveal about the ways this discipline addresses hope? Sociologists' hopes express themselves, among others, in representations of places that are envisaged as settings historically pregnant of other social orders. By focusing especially on urban u-topias brought about at the beginning of sociology in Germany, France, the United States and Brazil, and on their recent conceptual unfoldings, one realizes the methodological role that representations of time as to (urban) space play in the relations of sociology with hope. Particularly historical concepts of time regarding cities seem to be crucial for a "hopeful" sociology. KErWORDS: Sociology, Time, Space, U-topia, City.

Fraya Frehse é professora do Departamento de Sociologia da USP, onde coordena o Núcleo de Estudos e Pesquisas em Sociologia do Espaço. @ - fraya@usp.br

Recebido em 28.5.2012 e aceito em 12.6.2012. 